\title{
BMJ Open Prescriber barriers and enablers to minimising potentially inappropriate medications in adults: a systematic review and thematic synthesis
}

\author{
Kristen Anderson, ${ }^{1,2}$ Danielle Stowasser, ${ }^{3}$ Christopher Freeman, ${ }^{2,3}$ Ian Scott ${ }^{1,4}$
}

To cite: Anderson $\mathrm{K}$, Stowasser D, Freeman C, et al. Prescriber barriers and enablers to minimising potentially inappropriate medications in adults: a systematic review and thematic synthesis. BMJ Open 2014;4:e006544. doi:10.1136/bmjopen-2014006544

- Prepublication history and additional material is available. To view please visit the journal (http://dx.doi.org/ 10.1136/bmjopen-2014006544).

Received 4 September 2014 Revised 16 October 2014 Accepted 6 November 2014

CrossMark

For numbered affiliations see end of article.

Correspondence to Ms Kristen Anderson; k.anderson8@uq.edu.au

\section{ABSTRACT}

Objective: To synthesise qualitative studies that explore prescribers' perceived barriers and enablers to minimising potentially inappropriate medications (PIMs) chronically prescribed in adults.

Design: A qualitative systematic review was undertaken by searching PubMed, EMBASE, Scopus, PsycINFO, CINAHL and INFORMIT from inception to March 2014, combined with an extensive manual search of reference lists and related citations. A quality checklist was used to assess the transparency of the reporting of included studies and the potential for bias. Thematic synthesis identified common subthemes and descriptive themes across studies from which an analytical construct was developed. Study characteristics were examined to explain differences in findings.

Setting: All healthcare settings.

Participants: Medical and non-medical prescribers of medicines to adults.

Outcomes: Prescribers' perspectives on factors which shape their behaviour towards continuing or discontinuing PIMs in adults.

Results: 21 studies were included; most explored primary care physicians' perspectives on managing older, community-based adults. Barriers and enablers to minimising PIMs emerged within four analytical themes: problem awareness; inertia secondary to lower perceived value proposition for ceasing versus continuing PIMs; self-efficacy in regard to personal ability to alter prescribing; and feasibility of altering prescribing in routine care environments given external constraints. The first three themes are intrinsic to the prescriber (eg, beliefs, attitudes, knowledge, skills, behaviour) and the fourth is extrinsic (eg, patient, work setting, health system and cultural factors). The PIMs examined and practice setting influenced the themes reported.

Conclusions: A multitude of highly interdependent factors shape prescribers' behaviour towards continuing or discontinuing PIMs. A full understanding of prescriber barriers and enablers to changing prescribing behaviour is critical to the development of targeted interventions aimed at deprescribing PIMs and reducing the risk of iatrogenic harm.

\section{Strengths and limitations of this study}

This is the most comprehensive review to date of prescribers' barriers and enablers to minimising potentially inappropriate medications which are chronically prescribed in adults.

- Although database and manual searching was protracted and extensive, it is possible that not all relevant studies were found due to the poor indexing and inconsistent terminology for this topic.

- Utilisation of a peer-reviewed, published method for thematic synthesis and a checklist to assess potential bias in studies contributed to the review's methodological rigour.

- The included studies largely explored primary care physicians' perspectives on managing older, community-based adults in relation to relatively few drug classes and may limit the generalisability of the findings.

\section{INTRODUCTION}

Studies in the USA and Australia indicate that at least one in two older people (aged 65 years or greater) living in the community use five or more prescription, over-thecounter or complementary medicines every day, and the number used increases with age. $^{1}{ }^{2}$ Polypharmacy (the use of multiple medications concurrently) predisposes older people to being prescribed potentially inappropriate medications (PIMs), that is, where the actual or potential harms of therapy outweigh the benefits. ${ }^{3-5}$ Recent international data suggest that one in five prescriptions for community-dwelling older adults is inappropriate. ${ }^{6}$ In Australia, approximately $20-50 \%$ of individuals in this age group are prescribed one or more PIMs, with higher rates seen in residential aged care facilities (RACFs). ${ }^{3}{ }^{7-10}$ For adults younger than 65 years of age, rates of prescribing of PIMs have not been quantified beyond single medication classes (eg, benzodiazepines, 
proton pump inhibitors). The rates and harms of polypharmacy in this population remain uncertain, although they are likely to be considerably less than that seen in older adults. In contrast, the harms of polypharmacy and prescribing of PIMs in older people are well established. Prescribing of PIMs is independently associated with adverse drug events, hospital presentations, poorer health-related quality of life and death. ${ }^{11}{ }^{12} \mathrm{Up}$ to $15 \%$ of all hospitalisations involving older people in Australia are medication-related, with one in five potentially preventable. $^{13}$

These well-documented harms of prescribing PIMs should evoke a response from clinicians to identify and stop, or reduce the dose of, inappropriate medications as a matter of priority. While there is some evidence that PIM exposure has decreased marginally over recent years, its prevalence remains high. ${ }^{3}{ }^{14-16}$ The process of reducing or discontinuing medications, with the goal of minimising inappropriate use and preventing adverse patient outcomes, is increasingly referred to as 'deprescribing. ${ }^{17}$ Although the term may be new, appropriate cessation or reduction of medication is a long accepted component of competent prescribing. ${ }^{18} 19$

The act of stopping a medication prescribed over months to years, however, is complicated by many factors related to patients and prescribers. These need to be understood if effective deprescribing strategies are to be developed. A recent review by Reeve et $a l^{20}$ identified patient barriers to, and enablers of, deprescribing, but to the best of our knowledge, no comprehensive review of prescribers' perspectives has been reported, which this paper aims to provide.

\section{METHODS}

In the absence of a universally accepted method to conduct a systematic review of qualitative data, we utilised principles of quantitative systematic review, applied to qualitative research, ${ }^{21}$ and were guided by the Cochrane endorsed ENTREQ (Enhancing transparency in reporting the synthesis of qualitative research) position statement. ${ }^{22}$

\section{Search strategy and sources}

An initial search was conducted to ensure that no systematic review on the same topic already existed. Two experienced health librarians were independently consulted in developing a comprehensive search strategy, which was informed by extensive prior scoping. ${ }^{23}$

PubMed, EMBASE, Scopus (limited to Health Sciences), PsycINFO, CINAHL and INFORMIT (Health Collection) electronic databases were searched from inception to March 2014. Filters to identify qualitative research were used and adapted to improve search sensitivity. ${ }^{24}$ These were combined with terms and text words for: medical and non-medical prescribers and either inappropriate prescribing or reducing, stopping or optimising medications. Terms/text words were searched in all/any fields or restricted to the title, abstract or keyword, depending on the size of the database and sophistication of its indexing. Reference lists and related citations of relevant articles were reviewed for additional studies. The full search strategy is detailed in the online supplementary appendix.

\section{Study selection}

After duplicate citations were excluded, one reviewer (KA) screened titles, abstracts and, where necessary, full text, to create a list of potentially relevant full text articles. Articles were required to meet provisional, intentionally overly inclusive, eligibility criteria to minimise the risk of inappropriate exclusions by the single reviewer. This list was forwarded to three reviewers (CF, DS and IS) who independently assessed the articles for inclusion. Discrepant views were resolved by group discussion to create the final list of included papers based on the refined eligibility criteria.

\section{Inclusion and exclusion criteria}

Inclusion criteria comprised: (1) original research articles with a qualitative component (ie, qualitative, mixed or multimethod studies all accepted); and (2) focus on eliciting prescribers' perspectives of factors that influence their decision to continue or cease chronically prescribed PIMs (as defined by the authors of each study) in adults.

No limits were placed on the care or practice setting of the patient or prescriber, respectively, or whether the article related to single or multiple medications.

Exclusion criteria comprised: (1) reviews, papers not published in English, and those for which the abstract or full text were not available; (2) focus on medication management decisions in the final weeks of life; (3) focus entirely on initiation of PIMs and (4) reported only quantitative data derived from structured questionnaires.

\section{Assessment of the quality of studies}

One researcher (KA) assessed the reporting of studies using the Consolidated Criteria for Reporting Qualitative Research (COREQ) checklist. This reporting guideline, endorsed by the Cochrane Collaboration, assesses the completeness of reporting and potential for bias in studies of interviews or focus groups. ${ }^{25}$ Any instances of interpretive uncertainty arising from the checklist were discussed and resolved within the four investigators.

Studies were not excluded or findings weighted on the basis of the COREQ assessment. Rather, we elected to include all studies, ascribing to the theory that the value of insights contained within individual studies may only become apparent at the point of synthesis rather than during the appraisal process. ${ }^{26}$

\section{Data extraction process}

For all included articles, data were extracted about study aims, location, setting, study design, participants, recruitment, PIMs examined and prescribers' perspectives of 
factors influencing the chronic prescription of PIMs. Data for thematic analysis were only extracted from the results (not discussion) section of papers, with particular notice taken of quotations from prescriber participants.

\section{Synthesis of results}

The method used to synthesise results was based on the technique of thematic synthesis described by Thomas and Harden. ${ }^{27}$ Following multiple readings of the papers to achieve immersion, KA manually coded and extracted the text, and developed subthemes until no further subthemes could be identified. Two reviewers (DS and IS) independently read all papers and then reviewed the extracted, coded text and subthemes to confirm the comprehensiveness and reliability of the findings. ${ }^{28}$ Descriptive and draft analytical themes were subsequently developed by KA and then presented to, and discussed with, all investigators in developing and finalising the new analytical construct. The study characteristics and results were analysed for associations between specific themes and studies.

\section{RESULTS}

\section{Study selection}

The search yielded 6011 papers, 21 of which met the selection criteria (see figure 1). There were no studies exploring the perspectives of non-medical prescribers.

\section{Study characteristics}

The characteristics of included studies are presented in table 1. All but one, which collected data by survey, used focus groups and semistructured interviews to collect qualitative data. $^{29}$ Four papers explored prescribers' views in relation to multiple medications (ie, polypharmacy) ${ }^{30-33}$ while the remaining papers investigated prescribers' views in relation to single PIMs or classes of medications (10 described one or more centrally acting agents such as psychotropics, hypnotics, benzodiazepines, minor opiates and antidepressants ${ }^{34-43}$; 2 for proton pump inhibitors ${ }^{44}$ and 5 for miscellaneous PIMs defined according to prespecified criteria, a preset medication list or clinical judgement. ${ }^{29} 46-49$ Eighteen studies elicited the views of prescribers practising in primary care, ${ }^{29-41} 44-48$ one of the prescribers in secondary care, ${ }^{49}$ and two of the prescribers servicing RACFs. ${ }^{42} 43$

\section{COREQ assessment}

The completeness of reporting varied across studies, with an average of 17 (range 8-22) of 32 items from the COREQ checklist clearly documented (table 2). The single descriptive survey reported 9 of 24 applicable fields. ${ }^{29}$ See online supplementary table for the completed COREQ assessment for each study.

The lowest rates of reporting were observed in domain 1, meaning that researcher bias (poor confirmability) cannot be excluded. ${ }^{26}$ Greater transparency was apparent with domains 2 and 3 allowing comparatively better assessment of the credibility, dependability and transferability of study findings. For example, all studies reported the sample size and method and most reported a description of the sample and interview guide. There was consistency between raw data and interpretive findings in all papers except one in which the interpretation was so brief that its accuracy was considered doubtful. ${ }^{36}$ For five papers, it was unclear whether ethics approval was obtained. $^{2934434446}$

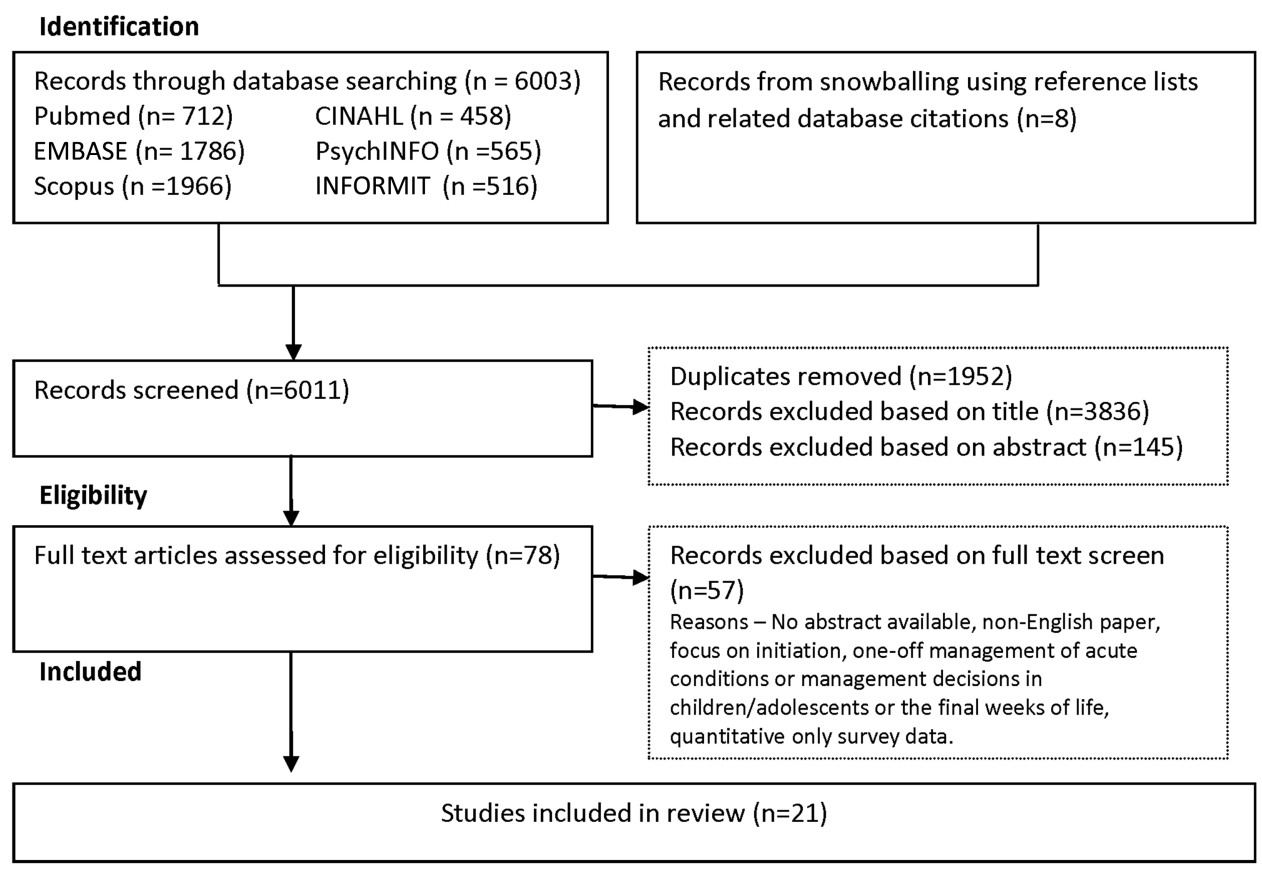

Figure 1 Flow chart of study selection. 


\begin{tabular}{|c|c|c|c|c|c|c|c|c|}
\hline $\begin{array}{l}\text { Year of } \\
\text { publication }\end{array}$ & $\begin{array}{l}\text { Lead } \\
\text { author }\end{array}$ & Country & Aim & Medication types & $\begin{array}{l}\text { Participants and } \\
\text { setting }\end{array}$ & $\begin{array}{l}\text { Age } \\
\text { focus* }\end{array}$ & Data collection method & Analysis \\
\hline 2007 & Cook & USA & $\begin{array}{l}\text { To understand factors } \\
\text { influencing the chronic use of } \\
\text { benzodiazepines in older adults }\end{array}$ & Benzodiazepines & $\begin{array}{l}33 \text { primary care } \\
\text { physicians }\end{array}$ & $\begin{array}{l}\text { Older } \\
\text { patients }\end{array}$ & $\begin{array}{l}\text { Face-to-face and telephone } \\
\text { SSIs }\end{array}$ & $\begin{array}{l}\text { Narrative } \\
\text { analysis }\end{array}$ \\
\hline 2007 & Rogers & England & $\begin{array}{l}\text { To explore the dilemma the } \\
\text { controversial benzodiazepine } \\
\text { legacy has created for recent } \\
\text { practitioners and their view of } \\
\text { prescribing benzodiazepines }\end{array}$ & Benzodiazepines & 22 GPs, primary care & All ages & SSIs & Not stated \\
\hline 2010 & Anthierens & Belgium & $\begin{array}{l}\text { To describe GPs' views and } \\
\text { beliefs on polypharmacy in order } \\
\text { to identify the role of the GP in } \\
\text { improving prescribing behaviour }\end{array}$ & Polypharmacy & 65 GPs, primary care & $\begin{array}{l}\text { Older } \\
\text { patients }\end{array}$ & $\begin{array}{l}\text { Face-to-face individual SSIs } \\
\text { (literature informed interview } \\
\text { guide) }\end{array}$ & $\begin{array}{l}\text { Content } \\
\text { analysis }\end{array}$ \\
\hline 2010 & Dickinson & UK & $\begin{array}{l}\text { To explore the attitudes of older } \\
\text { patients and their GPs to chronic } \\
\text { prescribing of antidepressant } \\
\text { therapy, and factors influencing } \\
\text { such prescribing }\end{array}$ & Antidepressants & 10 GPs, primary care & $\begin{array}{l}\text { Older } \\
\text { patients }\end{array}$ & SSIs & $\begin{array}{l}\text { Framework } \\
\text { analysis }\end{array}$ \\
\hline 2010 & Frich & Norway & $\begin{array}{l}\text { To explore GPs' and tutors' } \\
\text { experiences with peer group } \\
\text { academic detailing, and to } \\
\text { explore GPs' reasons for } \\
\text { deviating from recommended } \\
\text { prescribing practice }\end{array}$ & Miscellaneous PIMs & $\begin{array}{l}20 \text { GPs (39 GPs also } \\
\text { interviewed on topics } \\
\text { outside the scope of this } \\
\text { review) }\end{array}$ & $\begin{array}{l}\text { Older } \\
\text { patients }\end{array}$ & $\begin{array}{l}\text { Focus group interviews } \\
\text { following individual receipt of } \\
\text { prescription profile report }\end{array}$ & $\begin{array}{l}\text { Thematic } \\
\text { content analysis }\end{array}$ \\
\hline 2010 & Moen & Sweden & $\begin{array}{l}\text { To explore GPs' perspectives of } \\
\text { treating older users of multiple } \\
\text { medicines }\end{array}$ & Polypharmacy & $\begin{array}{l}31 \text { GPs (4 private, } 27 \\
\text { county-employed), } \\
\text { primary care }\end{array}$ & $\begin{array}{l}\text { Older } \\
\text { patients }\end{array}$ & $\begin{array}{l}\text { Focus groups (literature } \\
\text { informed question guide) }\end{array}$ & $\begin{array}{l}\text { Conventional } \\
\text { content analysis }\end{array}$ \\
\hline 2010 & Subelj & Slovenia & $\begin{array}{l}\text { To investigate how } \\
\text { high-prescribing family } \\
\text { physicians explain their own } \\
\text { prescription }\end{array}$ & Benzodiazepines & $\begin{array}{l}10 \text { family physicians ( } 5 \\
\text { high and } 5 \text { low } \\
\text { prescribers), primary } \\
\text { care }\end{array}$ & All ages & SSIs & Not stated \\
\hline 2011 & Fried & USA & $\begin{array}{l}\text { To explore clinicians' } \\
\text { perspectives of and experiences } \\
\text { with therapeutic decision-making } \\
\text { for older persons with multiple } \\
\text { medical conditions }\end{array}$ & Polypharmacy & $\begin{array}{l}36 \text { physicians, primary } \\
\text { care, vet affairs and } \\
\text { academia }\end{array}$ & $\begin{array}{l}\text { Older } \\
\text { patients }\end{array}$ & Focus groups & $\begin{array}{l}\text { Content } \\
\text { analysis }\end{array}$ \\
\hline 2011 & Iden & Norway & $\begin{array}{l}\text { To explore decision-making } \\
\text { among doctors and nurses on } \\
\text { antidepressant treatment in } \\
\text { nursing homes }\end{array}$ & Antidepressants & $\begin{array}{l}16 \text { doctors, } 8 \text { each } \\
\text { working full-time and } \\
\text { part-time in residential } \\
\text { aged care facilities }\end{array}$ & $\begin{array}{l}\text { Older } \\
\text { patients }\end{array}$ & Focus groups & $\begin{array}{l}\text { Systematic text } \\
\text { condensation } \\
\text { and analysis }\end{array}$ \\
\hline 2012 & Flick & Germany & $\begin{array}{l}\text { To explore, given the specific } \\
\text { risks and the limited effect of } \\
\text { sleeping medication, why } \\
\text { doctors prescribe hypnotics for } \\
\text { the elderly in long-term care } \\
\text { settings }\end{array}$ & Hypnotics & $\begin{array}{l}20 \text { prescribers servicing } \\
\text { residential aged care } \\
\text { facilities }\end{array}$ & $\begin{array}{l}\text { Older } \\
\text { patients }\end{array}$ & Episodic interviews & $\begin{array}{l}\text { Thematic } \\
\text { analysis }\end{array}$ \\
\hline
\end{tabular}




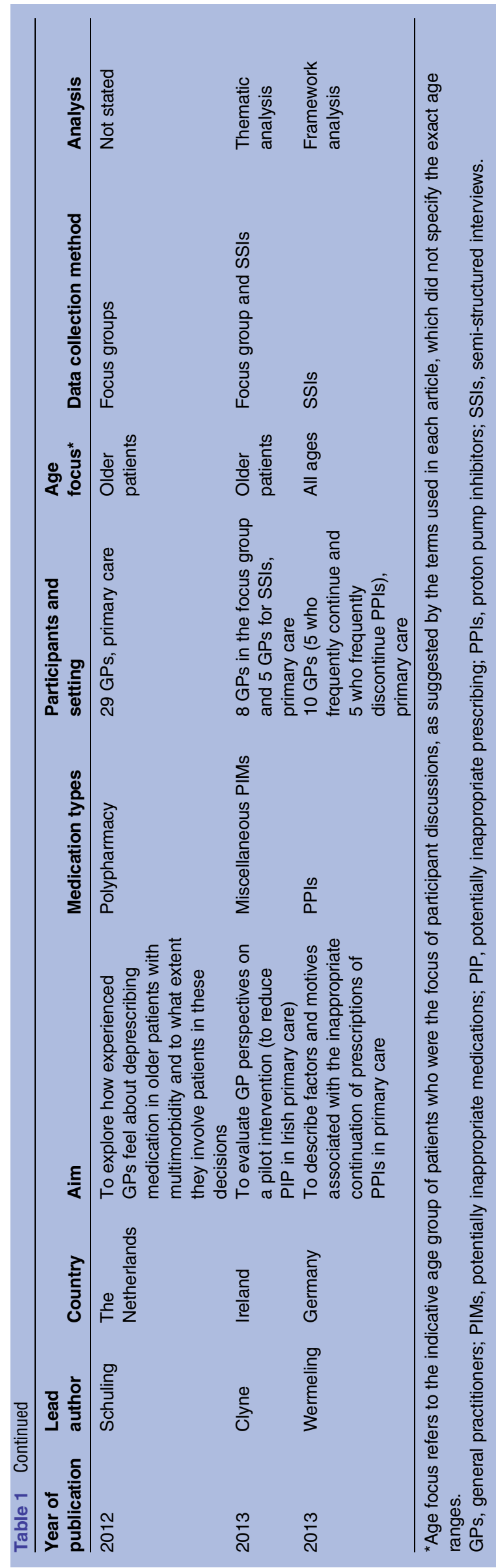

Synthesis of results

Thematic synthesis yielded 42 subthemes, 12 unique descriptive themes and 4 analytical themes (figure 2), with multiple interdependencies and relationships. Barrier and enabler descriptive themes and subthemes tended to mirror each other for each analytical theme of Awareness, Inertia, Self-efficacy and Feasibility. The first three themes reflect factors intrinsic to the prescriber and his/her decision-making process while the fourth deals with extrinsic factors. Tables 3 and 4 provide illustrative quotations from either primary study participants or study authors relating to barrier and enabler subthemes, respectively.

Fewer enablers were reported than barriers and there was variation in the relative contribution of each study to each theme.

\section{AWARENESS}

Awareness refers to the level of insight a prescriber has into the appropriateness of his/her prescribing. This theme was apparent in the three papers which utilised audit or informal third-party (eg, other health professional) observation and feedback. ${ }^{46} 4749$ Poor insight was an observed rather than reported barrier, with interventions to raise prescriber awareness an enabler to minimising the prescription of PIMs. Prescriber beliefs at a population level did not necessarily translate to prescribing practices at an individual level. For example, agreement among prescribers that benzodiazepines should not be used regularly or in the long term did not necessarily preclude such prescribing in individual patients. ${ }^{343841}$

\section{INERTIA}

Inertia is defined as the failure to act, despite awareness that prescribing is potentially inappropriate, because ceasing PIMs is perceived to be a lower value proposition than continuing PIMs.

Fear of unknown/negative consequences of change featured in 15 of 22 papers, and related to consequences for: the prescriber (threatened therapeutic relationship, diminished credibility, increased initial and ongoing workload, potential for litigation, conflict with other prescribers/health professionals) ${ }^{29-31} 34-36384043-4749$; the patient (withdrawal syndrome, symptom relapse or increased risk of the condition/event for which preventive medication was originally prescribed) ${ }^{36} \quad \begin{array}{llll}38 & 40 & 42-47\end{array}$ and other health professionals (increased workload and safety concerns of staff in RACFs).$^{42} 43$ The prescriber beliefs that facilitate cessation were the converse, that is, fear of unknown/negative consequences of continuation, ${ }^{44}$ a positive attitude to stopping medicines ${ }^{31}$ and a belief that this practice can bring benefits. ${ }^{36} 3748$

The barrier belief that drugs appear to work with few adverse effects was apparent in nine papers ${ }^{34} 353839$ $4143-4547$ of which two studied 'high-rate' and 'low-rate' benzodiazepine prescribers. 'High-rate' prescribers consistently downplayed risks of harm, whereas 'low/ 
Table 2 Comprehensiveness of reporting assessment (Consolidated Criteria for Reporting Qualitative studies checklist) ${ }^{25}$

\begin{tabular}{|c|c|c|}
\hline Reporting criteria & $\begin{array}{l}\text { Number of studies } \\
\text { reporting each criterion } \\
\mathrm{N}=\mathrm{x} \text { of } 21\end{array}$ & $\begin{array}{l}\text { References of studies } \\
\text { reporting each criterion }\end{array}$ \\
\hline \multicolumn{3}{|l|}{ Domain 1} \\
\hline \multicolumn{3}{|l|}{ Characteristics of research team } \\
\hline Interviewer/facilitator identified & 14 & $30-3437384244-49$ \\
\hline Credentials & 12 & $293033-3538-4042464749$ \\
\hline Occupation & 7 & $3438-40424649$ \\
\hline Gender & 16 & $30-35 \quad 37-39424345-49$ \\
\hline Experience and training & 2 & 3839 \\
\hline \multicolumn{3}{|l|}{ Relationship with participants } \\
\hline Relationship established before study started & 5 & 3436414445 \\
\hline Participant knowledge of the interviewer & 3 & 343641 \\
\hline Interviewer characteristics & 4 & 38394247 \\
\hline \multicolumn{3}{|l|}{ Domain 2} \\
\hline \multicolumn{3}{|l|}{ Study design } \\
\hline Methodological theory identified & 15 & $3032-3537384042-45 \quad 47-49$ \\
\hline \multicolumn{3}{|l|}{ Participant selection } \\
\hline Sampling method (eg, purposive, convenience) & 21 & $29-49$ \\
\hline Method of approach & 12 & 32343738 40-43 45-47 49 \\
\hline Sample size & 21 & $29-49$ \\
\hline Number/reasons for non-participation & 7 & 32343537404144 \\
\hline \multicolumn{3}{|l|}{ Setting } \\
\hline Setting of data collection & 11 & $29-3234363739414546$ \\
\hline Presence of non-participants & 0 & - \\
\hline Description of sample & 17 & $29-3437-454749$ \\
\hline \multicolumn{3}{|l|}{ Data collection } \\
\hline Interview guide & 16 & $29-353738 \quad 40-43464749$ \\
\hline Repeat interviews & 0 & - \\
\hline Audio/visual recording & 19 & $30-3537-49$ \\
\hline Field notes & 6 & 303237404247 \\
\hline Duration & 12 & $303133353741-454849$ \\
\hline Data saturation & 7 & $30313537-3944$ \\
\hline Transcripts returned to participants & 1 & 44 \\
\hline \multicolumn{3}{|l|}{ Domain 3} \\
\hline \multicolumn{3}{|l|}{ Data analysis } \\
\hline Number of data coders & 16 & 30-34 36 37 39-42 44-47 49 \\
\hline Description of coding tree & 15 & $30-343739-454749$ \\
\hline Derivation of themes & 18 & $30-3436-4749$ \\
\hline Software & 6 & 303840444849 \\
\hline Participant checking & 2 & 3749 \\
\hline \multicolumn{3}{|l|}{ Reporting } \\
\hline Participant quotations presented & 18 & $30-34 \quad 37-49$ \\
\hline Data and findings consistent & 20 & $29-35 \quad 37-49$ \\
\hline Clarity of major themes & 18 & $29-3437-4749$ \\
\hline Clarity of minor themes & 14 & $29-3133343637$ 39-41 43-45 49 \\
\hline
\end{tabular}

medium-rate' prescribers were more conscious of such risks. ${ }^{34} 41$ The futility and potential harm of cessation in patients of advanced age was a subtheme predominantly present in papers considering psychoactive agents.
Another barrier was the devolvement of responsibility

Another barrier was the devolvement of responsibility
to another party for the decision to continue or cease a medication (eg, another prescriber, health professional, society or the patient). One example was continuation of PIMs in patients that prescribers had inherited from colleagues where the former failed to question the rationale used by the latter in prescribing such drugs. ${ }^{29} 34 \quad 4149$ Another example was the provision of PIMs on the request of RACF nursing staff $^{42}$ or patients $^{34} 4043$ without a critical prescriber review. Finally, inappropriate prescribing of psychotropics, while viewed as a public health concern, was considered beyond the scope of individual prescribers. ${ }^{35}$

\section{SELF-EFFICACY}

This analytical theme refers to factors that influence a prescriber's belief and confidence in his or her ability to address PIM use. It involves subthemes relating to 


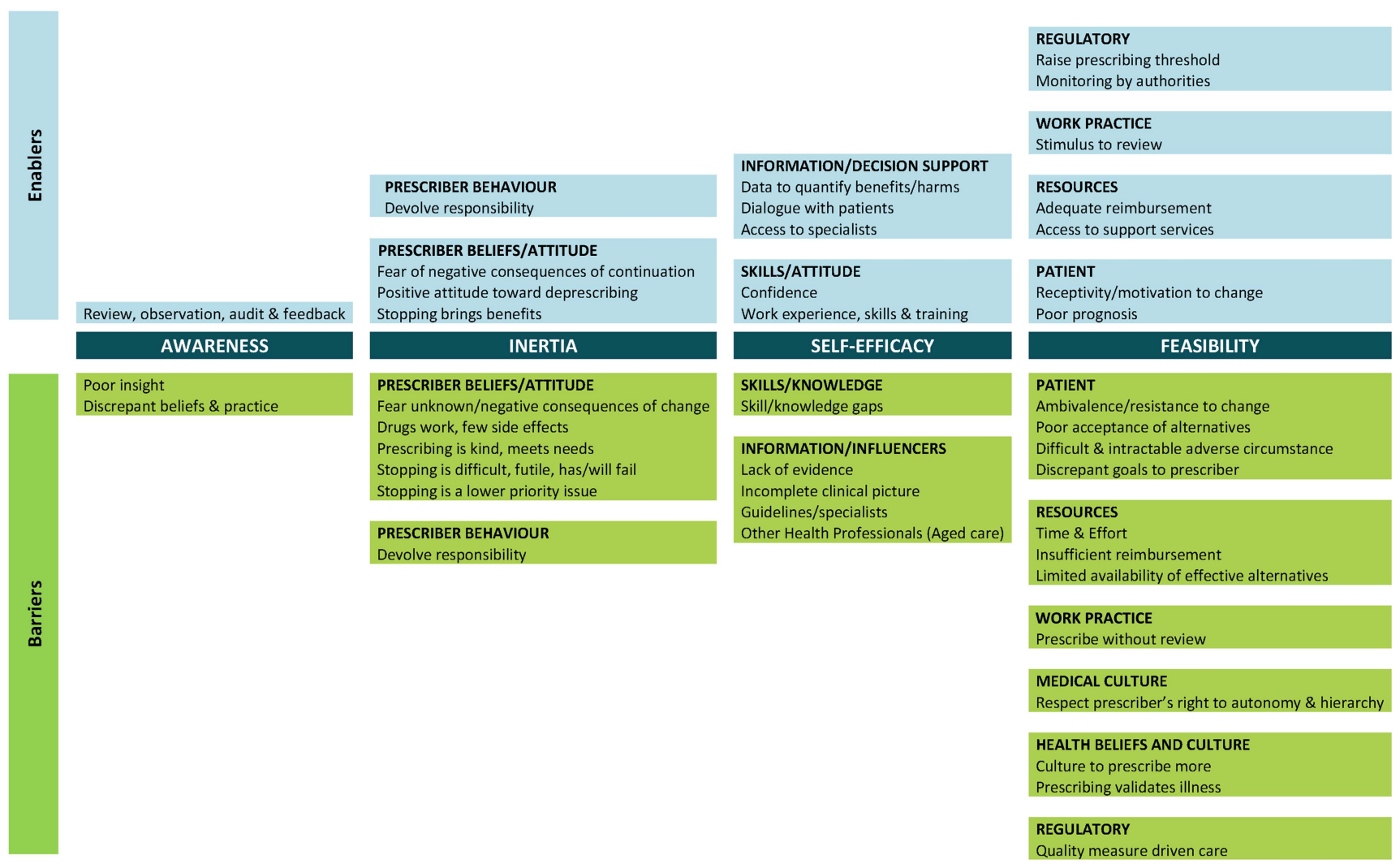

Figure 2 Schematic representation of barriers and enablers associated with each analytical and descriptive theme.

knowledge, skill, attitudes, influences, information and decision support.

Knowledge or skill deficits, ${ }^{30-35} 40 \quad 4549$ including difficulty in balancing the benefits and harms of therapy, ${ }^{30-33}$ recognising adverse drug effects ${ }^{31} 32$ and establishing clear-cut diagnoses/indications for medicines, ${ }^{34} 35{ }^{40}$ were challenges prescribers faced in identifying and managing PIMs. Balancing the benefits and harms was perceived to be especially difficult when reviewing preventive medications in multimorbid older people with polypharmacy where shorter life expectancy, uncertain future benefits and higher susceptibility to more immediate adverse drug effects must all be considered $^{30-33}$ On the other hand, better quantification of the benefits and harms of therapy, ${ }^{30-32}{ }^{48}$ confidence to deviate from guidelines and stop medications if thought necessary, ${ }^{33}{ }^{45}$ greater experience, ${ }^{30} 45$ and targeted training, especially in prescribing for older people, ${ }^{49}$ were seen as enabling factors.

Compounding generic knowledge and skill gaps were information deficits specific to individual prescribing decisions, resulting from poor communication with multiple prescribers and specialists involved in patient care, inadequate transfer of information at care interfaces, fragmented and difficult-to-access patient medical records, and failure of patients to know/disclose their full medical history/medication lists to prescribers. ${ }^{30-33}$

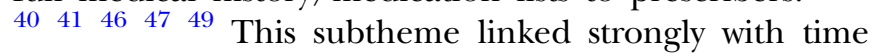
and effort demands on prescribers, and in two papers was associated with low motivation arising from a perceived inability to efficiently access all information required for optimal prescribing. ${ }^{40} 49$

Eight papers discussed the influence of care recommendations from guidelines and specialists. ${ }^{30-33} 38444649$ Guidelines were often viewed negatively, with prescribers feeling pressured to comply with recommendations at odds with the complexities of clinical practice. ${ }^{30-32} 4446$ Pressure from staff to continue prescribing PIMs, often to maintain facility routines, was presented as a barrier unique to RACFs. ${ }^{42}{ }^{43}$ Offsetting this were enablers centred on greater dialogue with patients to increase understanding and facilitate shared decisionmaking, ${ }^{29} 30314446$ as well as timely access to, and decision support from, specialists, particularly geriatricians and psychiatrists. 374041444649

\section{FEASIBILITY}

Feasibility refers to factors, external to the prescriber, which determine the ease or likelihood of change. They relate to patient characteristics, resource availability, work practices, medical and societal health beliefs and culture, and regulations.

The most frequently expressed barrier concerning patients was their ambivalence or resistance to change ${ }^{29-32}$ 353738404344464849 and their poor acceptance of alternative therapies. ${ }^{37} 38$ 42-44 In contrast, receptivity and capacity to change were identified as enablers in three 
Illustrative quotations

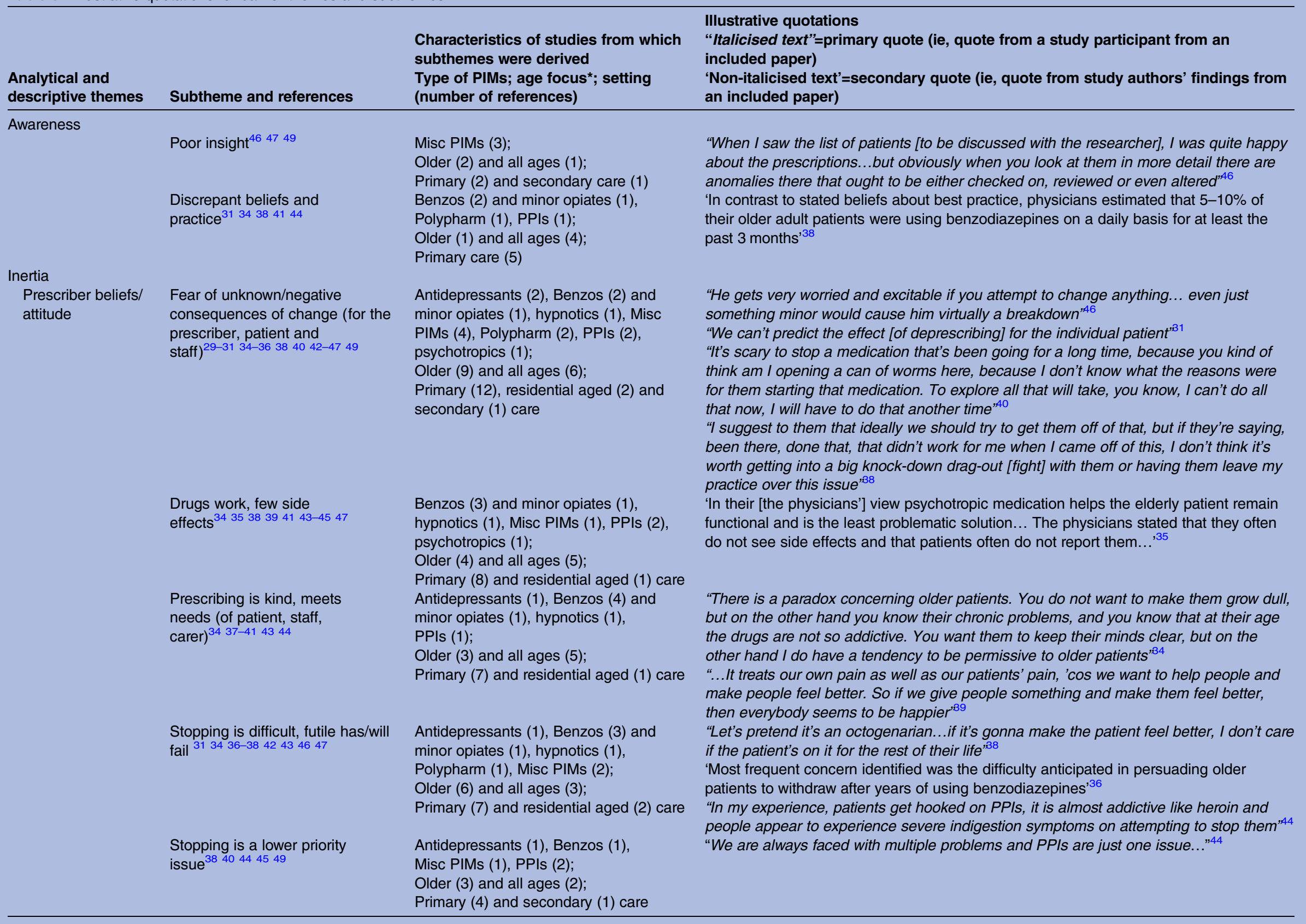


Analytical and

descriptive themes

Prescriber

$\begin{array}{ll}\text { Prescriber } & \text { Devolve responsibility } 2934 \\ \text { behaviour } & 3540-4349\end{array}$

Subtheme and references

Self-efficacy

Skills/knowledge Skills/knowledge

gaps $^{30-35404549}$

Information/

influencers

Lack of evidence ${ }^{3031} 33$

Incomplete clinica Incomplete clinical
picture $^{30-334041464749}$ Guidelines/specialists
38444649

Other health professionals (aged care) 4243
Characteristics of studies from which subthemes were derived

Type of PIMs; age focus*; setting (number of references)

Antidepressants (2), Benzos (1) and minor opiates (1), hypnotics (1), Misc PIMs (2), psychotropics (1); Older (5) and all ages (3); Primary (5), secondary (1) and residential aged (2) care

Antidepressants (1), Benzos and minor opiates (1), Misc PIMs (1), Polypharm (4), PPIs (1), psychotropics (1); Older (7) and all ages (2);

Primary (8) and secondary (1) care

Polypharm (3);

Older age (3);

Primary care (3)

Antidepressants (1), Benzos (1)

Misc PIMs (3), Polypharm (4);

Older (7) and all ages (2);

Primary (8) and secondary (1) care

Benzos (1), Misc PIMs (2),

Polypharm (4), PPIs (1);

Older (6) and all ages (2);

Primary (7) and secondary (1) care

Antidepressants (1) and hypnotics (1); Older patients (2); Aged care (2)
Illustrative quotations

"Italicised text"=primary quote (ie, quote from a study participant from an included paper)

'Non-italicised text'=secondary quote (ie, quote from study authors' findings from an included paper)

'They [the physicians] recognized that the inappropriate use of psychotropic medication for elderly patients was a public health problem, but they felt that it was beyond the scope of the individual physician, 35

“(...) I ask them if it should be a sleeping pill or another of the available options and mostly they have a need for sleeping pills"43

"I have been running this practice for twelve years. I took it over from an older colleague. I took over all his patients. They were mostly old people. Prescribing policy has been rather liberal, and I have continued this policy ${ }^{134}$

"I don't have enough time for education about the newest information on psychiatric disorders, and better communication with specialists would be very helpful't1 'Side effects are not always recognised as such' 32

"When house officers come on our ward, they haven't necessarily been trained in geriatrics. So they arrive here, and then they start with $10 \mathrm{mg}$ of morphine every four hours. That's too much" (Hospital based geriatrician) ${ }^{49}$

"You look at the medication list and want to reduce it but then you can't find things you can eliminate, ${ }^{\text {, } 11}$

"To me, the guidelines are kind of a hindrance. At the moment they do not cater for older patients's1

"The problem is that the medication lists of the doctors involved are not exchanged and are consequently inconsistent $t^{31}$

"One has discovered that they might have completely different expectations than what the doctor had from the beginning. Do they want to survive for five more years or? And so on. What are their expectations?'B0

'Medicines, (mainly for chronic conditions) were sometimes not appropriately reviewed because there was no written information on indication and follow-up or because this was not readily available,49

"Sometimes the older people decide for themselves to reduce some of their medication or to adjust the doses without telling their GP. Therefore as their GP you can have the wrong impression about their medication intake..."32

When existing guidelines are debated, GPs felt deceived and insecure... The importance of individualising treatment was also expressed and many guidelines were perceived as too rigid leading to a standardized 'kit' of medicines per indication...,30

"I have difficulty not following the guidelines if I don't have good reasons to do so", "When the hospital consultant recommends a treatment it's difficult... for us not to prescribe unless there is a very good reason. To some extent we feel obliged to carry on when they have initiated it ${ }^{46}$

"(...) in such a situation it amounts to the sleeping pill, because everybody else's need is the sleeping pill, and I would have to fight tooth and nail if really I wanted to avoid this ${ }^{43}$

- 
Characteristics of studies from which subthemes were derived

Analytical and

descriptive themes

Subtheme and references

Type of PIMs; age focus*; setting

(number of references)

Feasibility

Patient

.

Resources

Work practices
Ambivalence/resistance to change 29-32 3537384043 change 444849

Poor acceptance of alternatives $^{37} 38$ 42-44

Difficult and intractable adverse circumstance ${ }^{34} 35373940$

Discrepant goals to prescriber

Time and effort ${ }^{30} 3334373840-$

Insufficient reimbursement ${ }^{37} 38$

Limited availability of effective alternatives ${ }^{37} 38$ 41-43

Prescribe without review ${ }^{34} 35424345-47$
Antidepressants (1), Benzos (2), hypnotics (1), Misc PIMs (4), Polypharm (3), PPIs (1), psychotropics (1); Older (9) and all ages (4); Primary (11), secondary (1) and residential aged (1) care Antidepressants (1), Benzos (2), hypnotics (1), PPIs (1); Older (3) and all ages (2);

Primary (3) and residential aged (2) care Antidepressants (1), Benzos (2) and minor opiates (1), psychotropics (1); Older (2) and all ages (3);

Primary care (5)

Polypharm (2);

Older age (2);

Primary care (2)

Antidepressants (2), Benzos (3) and

minor opiates (1), Misc PIMs (3),

Polypharm (2);

Older (7) and all ages (4);

Primary (9), secondary (1) and

residential aged (1) care

Benzos (2);

Older (1) and all ages (1)

Primary (2) care

Antidepressants (1), Benzos (3),

hypnotics (1):

Older (3) and all ages (2);

Primary (3) and residential aged (2) care

Antidepressants (1), Benzos and minor

opiates (1), hypnotics (1), Misc PIMs (2),

PPIs (1), psychotropics (1);

Older (4) and all ages (3);

Primary (5) and residential aged (2) care

Illustrative quotations

"Italicised text"=primary quote (ie, quote from a study participant from an included paper)

'Non-italicised text'=secondary quote (ie, quote from study authors' findings from an included paper)

"They (RACF nurses) called me on the carpet to tell me that withdrawing antidepressants was not a clever thing to do because the patient became angrier and resisted care. They therefore demanded that I reinstate medication, 42

"When I said initially we wanted her to come off it, she said, oh no, l've been on that for ages, and I don't want to come off it ${ }^{\text {,48 }}$

"The discontent rarely lies with the patient themselves"31

"...these types of people and they tend not to want to help themselves, you know they won't take the hypnotherapy and they won't go to yoga classes and they won't do anything else. They just want a quick fix ${ }^{\prime 37}$

"I think they have horrible lives, a lot of them... I think it's a combination of all things, their health, their social circumstances... I think a lot of people are on antidepressants because of everything put together. And you can't... change most of the factors that cause it ${ }^{\text {,40 }}$

"I kind of get aggravated that half of the medicines that I think are totally rubbish are the ones that the patient really wants to take,33

"We have a big problem with long-term hypnotic use. It would take an awful lot of work and it's purely a time and work problem,46

'A lack time or resources to provide counselling, especially due to the absence of remuneration for doing so, 37

'...There is hardly any alternative to medicamentous therapy ${ }^{33}$

"(...) then he gets something and he continues this pill, and then the issue is over for him, then it's quiet, and then he has his pill and then he sleeps through, and from time to time you may enquire, it if occurs to you while looking at his medication,"43 "When we work in a large health centre, then we sign prescriptions for each other... when a colleague is absent, we issue prescriptions for him that day. Any prescription I issue is my responsibility, but if you are asked to prescribe a particular drug [for a colleague] then you sign it in the reception. I don't check which other drugs that person uses $^{\prime 47}$ 


\begin{tabular}{|c|c|c|c|}
\hline $\begin{array}{l}\text { Analytical and } \\
\text { descriptive themes }\end{array}$ & Subtheme and references & $\begin{array}{l}\text { Characteristics of studies from which } \\
\text { subthemes were derived } \\
\text { Type of PIMs; age focus*; setting } \\
\text { (number of references) }\end{array}$ & $\begin{array}{l}\text { Illustrative quotations } \\
\text { "Italicised text"=primary quote (ie, quote from a study participant from an } \\
\text { included paper) } \\
\text { 'Non-italicised text'=secondary quote (ie, quote from study authors' findings from } \\
\text { an included paper) }\end{array}$ \\
\hline Medical culture & $\begin{array}{l}\text { Respect prescriber's right to } \\
\text { autonomy and hierarchy } \\
29303437454649\end{array}$ & $\begin{array}{l}\text { Benzos (1) and minor opiates (1), } \\
\text { Misc PIMs (3), Polypharm (1), PPIs (1); } \\
\text { Older (2) and all ages (5); } \\
\text { Primary (6) and secondary (1) care }\end{array}$ & $\begin{array}{l}\text { 'The GPs rarely contact colleagues, for example, hospital specialists, as there is a } \\
\text { perceived lack of routines for this as well as an informal understanding not to pursue } \\
\text { colleagues' motivations for prescriptions }{ }^{30}\end{array}$ \\
\hline \multirow[t]{2}{*}{$\begin{array}{l}\text { Health beliefs and } \\
\text { culture }\end{array}$} & Culture to prescribe more 324247 & $\begin{array}{l}\text { Antidepressants (1), Misc PIMs (1), } \\
\text { Polypharm (1); } \\
\text { Older patients (3), } \\
\text { Primary (2) and residential aged (1) care }\end{array}$ & $\begin{array}{l}\text { "The number of medications grows slowly. There is a complaint, we give new } \\
\text { medication, it continues without really stopping it after a while... and it is our } \\
\text { responsibility to try and withdraw it from the patient"32 }\end{array}$ \\
\hline & $\begin{array}{l}\text { Prescribing validates } \\
\text { illness } 344043\end{array}$ & $\begin{array}{l}\text { Antidepressants (1), Benzos and minor } \\
\text { opiates (1), hypnotics (1); } \\
\text { Older (2) and all ages (1); } \\
\text { Primary (2) and residential aged (1) care }\end{array}$ & $\begin{array}{l}\text { "They feel that unless they are on a tablet for it then they are not having any treatment. } \\
\text { There are a lot of those kinds of people" } 40\end{array}$ \\
\hline Regulatory & $\begin{array}{l}\text { Quality measure } \\
\text { driven care } \\
33\end{array}$ & $\begin{array}{l}\text { Polypharm (1); } \\
\text { Older (1); } \\
\text { Primary care (1) }\end{array}$ & $\begin{array}{l}\text { "Another factor that we experience at the VA is these electronic reminders that tell you to } \\
\text { do things... What I do really depends on who is in front of me...So the reminder comes } \\
\text { up and it makes no sense. This guy's } L D L \text { is } 101.8 . . \text { Should I go from } 40 \text { to } 80 \text { of } \\
\text { simvastatin? And what's the risk and benefit there?"33 }\end{array}$ \\
\hline
\end{tabular}

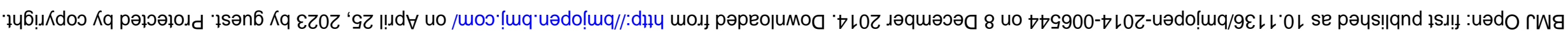


Analytical and

\section{descriptive}

themes

Awareness

Inertia

Prescriber

beliefs/attitude

Subtheme

Review, observation, audit and feedback 464749

Fear of negative/unknown consequences of continuation

Characteristics of studies from which subthemes were derived including: type of PIMs; age focus* setting (number of references)

Misc PIMs (3);

Older (2) and all ages (1)

Primary (2) and secondary (1) care

PPIs (1);

All ages (1);

Primary care (1)

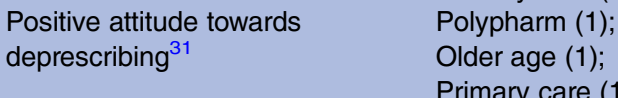

$\begin{array}{ll}\begin{array}{l}\text { Positive attitude towards } \\ \text { deprescribing }^{31}\end{array} & \text { Polypharm (1); } \\ & \text { Older age (1); } \\ & \text { Primary care (1) }\end{array}$

Stopping brings benefits ${ }^{36} 3748$ Benzos (2) and Misc PIMs (1);

Older (2) and all ages (1);

Primary care (3)

Prescriber

behaviour

Devolve responsibility 294044

Antidepressants (1), Misc PIMs (1), PPIs (1);

Older (1) and all ages (2);

Primary care (1)

Self-efficacy

Skills/attitude

Confidence (to stop therapy/ deviate from guidelines) 3345

Polypharm (1), PPIs (1);

Older patients (1) and all ages (1);

Primary care (2)

Work experience, skills and training 304549

Information/ Data to quantify benefits/ decision support harms ${ }^{30-3248}$

Dialogue with
patients $^{2930314446}$

Access to specialists 40414449

Antidepressants (1), Benzos (1), Misc PIMs (1) PPIs (1);

Older (2) and all ages (2);

Primary (3) and secondary (1) care

Misc PIMs (1), Polypharm (1), PPIs (1)

Older (2) and all ages (1);

Primary (2) and secondary (1) care

Misc PIMs (1), Polypharm (3);

Older (4);

Misc PIMs (2), Polypharm (2), PPIs (1);

Older (2) and all ages (3);

Primary care (5)
Illustrative quotations

"Italicised text"=primary quote (ie, quote from a study

participant from an included paper)

'Non-italicised text'=secondary quote (ie, quote

from study authors' findings from an included paper)

As above ${ }^{46}$

"Miracle all right, but too good of anything can be dangerous. Would just like to reiterate that, let me say they [PPIs] even work too well, what worries me is won't there be long-term missed cancers?"44

"You can have a field day with crossing off medication: 'sure, scrap half of it"

"O ya, and she was delighted, I stopped some of her other medications because she was in front of me and I had a bit of time to do it ${ }^{\text {th }}$

'Some [GPs] preferred to wait until the patient went to hospital where they would be taken off their drugs without the GP being blamed. The GP might even write and ask a hospital doctor to do this ${ }^{29}$

"Why not be honest and say, the NHS can't afford to keep giving you these drugs unless there's a very good reason. The patients understand that, and in this day and age they understand perfectly well about cost $t^{34}$

"It's not as if the life of the patient is suddenly at risk because I take away a pill, yes. [...] in the worst case heartburn may re-occur or there is upper abdominal discomfort, but that will not immediately cause a bleeding ulcer ${ }^{\text {A55 }}$ "I sort of you know tone those goals down. I am not looking for a Hemaglobin A1C of 7 anymore...so I take the pressure off them and I start removing those medications especially the ones that cause hypoglycaemia,33

"Because actually what you could do is to give him (patient) some more 'hard core' facts like: 'If you refrain from treatment your chance of stroke is $20 \%$...

'Discussion during the research interview made some patients more willing to consider a change in medication,29

'Adequate discussion with patients was widely recognised as one of the keys to influencing change, but although practiced by some GPs it was not always successful' 46

'They (low benzodiazepine prescribing family physicians) desired better co-operation and clear instructions from psychiatrists' ${ }^{4}$ 


\section{Analytical and}

\section{descriptive}

themes

Feasibility

Patient Subtheme

Receptivity/motivation to change
333746

Poor prognosis ${ }^{49}$

Adequate reimbursement ${ }^{38}$

Access to support

services $^{31} 374146$

Work practice

Stimulus to

review 293140444849

Regulatory

Raise the prescribing threshold

Raise

Monitoring by authorities ${ }^{34}$
Characteristics of studies from which subthemes

were derived including: type of PIMs; age focus* setting (number of references)

Benzos (1), Misc PIMs (1), Polypharm (1); Older (1) and all ages (2);

Primary care (3)

Misc PIMs (1);

Older age (1);

Secondary care (1)

\section{Benzos (1);}

Older age (1);

Primary care (1)

Benzos (2), Polypharm (1), Misc PIMs (1);

Older (1) and all ages (3);

Primary care (4)

Antidepressants (1), Misc PIMs (3); Polypharm (1),

PPIs (1);

Older (4) and all ages (2);

Primary (5) and secondary (1) care

PPIs (2);

All ages (2);

Primary care (2)

Benzos and minor opiates (1);

All ages (1);

Primary care (1)
Illustrative quotations

"Italicised text"=primary quote (ie, quote from a study

participant from an included paper)

'Non-italicised text'=secondary quote (ie, quote

from study authors' findings from an included paper)

"He's fairly amenable to tinkering with his pills, so we'll look at that"46

"Sometimes people have taken 10 medicines while they were in curative care, and gradually they move on to palliative care. Then we must reconsider all the prescriptions, drug by drug, saying: OK, what's the goal? To improve your comfort? Well, this medicine will make you feel more comfortable; we can stop this other one,49

"Reimbursement is very low...I think if it was something that we did get reimbursed on I think you would see physicians' attitudes a lot different. You'd be more willing to spend time,38

'Most GPs work closely with a local pharmacist [when undertaking medication review to stop medicines]: the task perception of such pharmacists was an important factor when a GP was looking for decision support in medication review ${ }^{31}$

'A new patient entering the practice list is welcomed as an opportunity to review their medication, ${ }^{31}$

"I think we are all sitting here and debating about this mainly because of the pressure on us by our pharmaceutical advisors not to prescribe PPIs because of cost implications to the NHS; I bet that this will not be an important topic in 2 years when Losec goes generic, 4

'The continuous monitoring of prescriptions by health authorities also put stress on the doctors ${ }^{34}$

${ }^{*}$ Age focus refers to the indicative age group of patients who were the focus of participant discussions, as suggested by the terms used in each article, which did not specify the exact age ranges.

Benzos, benzodiazepines; Misc, miscellaneous; PIMs, potentially inappropriate medications; Polypharm, polypharmacy; PPIs, proton pump inhibitors. 
studies, ${ }^{33} 3746$ as was a poor prognosis which helped crystallise care goals and prompt review of the appropriateness of existing drug regimens. ${ }^{49}$

The limited time and effort to review and discontinue medications $^{30} \quad 33 \quad 34 \quad 37 \quad 38 \quad 40-42 \quad 46 \quad 48 \quad 49$ was the most common resource constraint followed by the limited availability of effective non-drug treatment options. ${ }^{35} 37$ 38 41-43 Adequate reimbursement ${ }^{38}$ and access to support services such as mental health workers and pharmacists for medication review ${ }^{31} 374146$ emerged as enablers.

Certain work practices were raised as barriers to deprescribing, such as provision of repeats for a prescriber's own or colleague's patients, ${ }^{34} 4647$ and the absence of explicit treatment plans or a formal or scheduled medication review. ${ }^{34} 43$ The mirroring enablers were opportunities to review medication regimens (eg, hospital admission, ${ }^{29} 49$ change of prescriber, ${ }^{31}$ specialist $^{40}$ or scheduled review). ${ }^{44} 48$

The remaining descriptive themes related to medical and societal health beliefs and cultural and regulatory factors. The most frequently mentioned barrier was discomfort and reluctance to question a colleagues' pre-

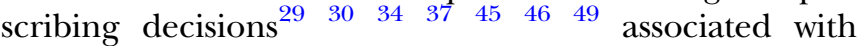
respect for professional autonomy or the medical hierarchy when specialist prescribers were involved.

Externally imposed guideline-based quality measures were presented as a barrier to minimising the prescription of PIMs. ${ }^{33}$ Raising the prescribing threshold for medications (eg, through increased cost or restricted access) ${ }^{44} 45$ and monitoring by authorities ${ }^{34}$ were seen by prescribers as unwelcome, perverse enablers.

\section{DISCUSSION}

This systematic review comprehensively investigates prescriber barriers and enablers to minimising the prevalence of chronically prescribed PIMs in adults. The thematic construct which was developed from published literature centres on Awareness, Inertia, Self-efficacy and Feasibility. It principally reflects the perspectives of primary care physicians managing older, communitybased adults. Although the themes and subthemes have been presented separately, the reasons doctors continue to prescribe, or do not cease, PIMs are multifactorial, highly interdependent and impacted by considerable clinical complexity.

Many subthemes were common to papers regardless of interstudy differences in the PIMs discussed, patient age and clinical setting (eg, primary, secondary or residential aged care).

Subthemes varied according to whether studies focused on polypharmacy or single PIMs or classes of PIMs, which were also associated with differing levels of prescriber insight and certainty. In the four studies focused on polypharmacy, prescribers were aware of polypharmacy-related harm but could not easily identify which medications were inappropriate, as reflected by the subthemes 'difficulty/inability to balance benefits and harms of therapy', ${ }^{30-33}$ 'inability to recognise adverse drug effects', 31 '32 'lack of evidence,"30 3133 and 'incomplete clinical picture'. ${ }^{30-33}$ In other studies focusing on specific classes of overprescribed medications, prescribers were aware of this inappropriateness, but in response voiced various rationalisations for continued prescribing such as 'drugs work, few adverse effects', $34 \quad 35 \quad 38 \quad 39 \quad 41 \quad 43-45 \quad 47$ 'prescribing is kind and meets needs', 34 37-41 4344 'stopping is difficult, futile, has or will fail', 34 36-38 424347 'poor (patient) acceptance of alternatives', $373842-44$ and 'difficult and intractable adverse ( patient) circumstance'. 3435373940

However, in other studies focusing on miscellaneous PIMs, prescribers were generally not aware of their inappropriate prescribing until this was revealed to them (eg, through audit and feedback). ${ }^{46} 4749$

No definite thematic pattern was observed from the subthemes of six studies which did not specifically focus on the care of older people $2937 \quad 394144 \quad 45$ compared with the remaining 15 which did. Compared with studies in primary care, unique themes emerged from papers set in RACFs and acute care settings. For example, pressure on prescribers to continue prescribing PIMs at the request of RACF nursing staff was unique to this setting. ${ }^{42} 43$ The one study set in acute care highlighted inexperience and training deficiencies of junior prescribers, as viewed by three geriatricians. ${ }^{49}$

The finding that poor insight into potentially inappropriate prescribing (PIP) practices was only apparent in studies where prescribers were made aware of this is unsurprising given that prescribers do not intentionally prescribe medications inappropriately. It demonstrates the importance of awareness-raising strategies for prescribers. Inertia, as in failure to deprescribe when appropriate, sits at odds with the more traditional use of the word as symbolising failure to intensify therapy when indicated. ${ }^{50}$ Inertia has been linked to 'omission bias' where individuals deem harm resulting from an act of commission to be worse than that resulting from an act of omission. ${ }^{51} 52$ In the case of deprescribing as an act of commission, it becomes more a matter of reconciling a level of expected utility (accrual of benefits) with a level of acceptable regret (potential to cause some harm). ${ }^{53}$ Fear of negative consequences resulting from deprescribing contributes to inertia and is not easily allayed by the current limited evidence base regarding the safety and efficacy of deprescribing. ${ }^{54}$ In the same papers in which prescribers rationalised continuation of therapy with the belief that drugs work and have few adverse effects, ${ }^{34} 3538 \quad 3941 \quad 43-4547$ prescribers also identified different thresholds for initiating versus continuing the same therapy. This anomaly suggests a lack of prescriber insight, clear differences in prescribers' attitudes towards initiation versus continuation, or a social response bias towards a false belief induced by the methodology used by interviewers. 
Relevance to previous literature

One meta-synthesis of seven papers has recently been published online exploring prescribers' perspectives of why PIP occurs in older people. ${ }^{55}$ Compared with our review, this study had a generic focus on PIP, including underprescribing, and its search strategy retrieved fewer articles $(n=7)$. Scanning their reference list did not reveal any additional papers which would have met our selection criteria and their results yielded no additional themes.

Our findings are consistent with those in the literature (largely focused on initiation of therapy), suggesting that pharmacological considerations are not the only factors impacting doctors' prescribing decisions. ${ }^{56}$ Interacting clinical, social and cultural factors relating to both the patient and prescriber influence prescribing decisions. ${ }^{56-58}$

Reeve $e t a l^{20}$ recently published a review of patient barriers and enablers to deprescribing and have emphasised the importance of a patient-centred deprescribing process. ${ }^{59}$ When comparing their results with ours, we find that prescribers' barriers are concordant with those of patients with respect to resistance to change, poor acceptance of non-drug alternatives, and fear of negative consequences of discontinuation. However, prescribers also underestimate enabling factors including patients' experiences/concerns of adverse effects, dislike of multiple medicines, and being assured that a ceased medication can be recommenced if necessary. Patients also reported that their primary care physician could be highly influential in encouraging them to discontinue therapy, a perception not echoed among prescribers in this review. ${ }^{20}$ Prescribers need to discuss, rather than assume, patient attitudes towards their medicines and to deprescribing, in the context of their current care goals.

Previous reviews of interventions to reduce inappropriate prescribing/polypharmacy in older patients have not been able to conclude with certainty that multifaceted interventions are more effective than single strategies. ${ }^{6061}$ Although our findings suggest that the former are likely to be more successful, further research is required to identify the barriers and enablers with the greatest potential for impact in designing targeted deprescribing interventions.

\section{Strengths and limitations}

Inconsistent terminology and poor indexing of search terms relating to deprescribing and inappropriate therapy greatly hampered our ability to identify relevant studies. Our mitigation efforts comprised a comprehensive prescoping exercise, a highly iterative search strategy tailored to each database, and snowballing from reference lists and related citations.

Despite no search restrictions on patient age, clinical setting or type of PIM, most study participants were experienced primary care physicians caring for older, community-based adults. Caution is therefore needed when transferring our results to other settings or patient groups. However, two recent cross-sectional studies looking at barriers to discontinuation of benzodiazepines and antipsychotics in nursing homes reflected subthemes identified in our review-fear of negative consequences of discontinuation such as poorer quality of life, symptom recurrence, greater workload and a lack of available, effective, non-drug alternatives. ${ }^{62} 63$

Many of the papers focused on relatively few drug classes (psychotropics and PPIs) and only four focused on polypharmacy. Although some subthemes were common to all types of studies (single and miscellaneous PIMs and polypharmacy papers), others were not. It is possible that, had more medication classes been studied, some of our results may have been different.

The strengths of our review include adherence to a peer-reviewed, documented methodology for thematic synthesis, COREQ assessment of studies allowing the assessment of potential for bias, compliance with ENTREQ reporting requirements and a multidisciplinary team of investigators to validate theme identification and synthesis.

\section{Implications for clinicians and policymakers} and future research

The results of this review disclose prescriber perceptions of their own cognitive processes as well as patient, work setting and other health system factors which shape their behaviour towards continuing or discontinuing chronically prescribed PIMs. The thematic synthesis provides a clear conceptual framework to understand this behaviour. Rendering these issues visible for both clinicians and policymakers is the first stage in minimising inappropriate prescribing in routine clinical practice. It facilitates what has been lacking in deprescribing intervention studies to date-a pragmatic approach towards identifying and accounting for local barriers and enablers which will determine the overall effectiveness of targeted interventions.

Further high-quality prospective clinical trials are urgently needed in demonstrating the safety, benefits and optimal modes of deprescribing, especially in relation to multimorbid older people. ${ }^{61}{ }^{64}$ The fog of polypharmacy clouds a prescriber's capacity and confidence to identify PIMs which, to be overcome, requires complete and accurate clinical information and decision support.

Professional organisations and colleges have an important role in encouraging the necessary cultural and attitudinal shifts towards 'less can be more' in appropriate patients. The push for guideline adherence and intensification of therapy needs to be counterbalanced by the view that judicious reduction, discontinuation or non-initiation of medication, in the context of shared decision-making and agreed care goals, is an affirmation of highest quality, individualised care. ${ }^{65}$ This view needs to be embraced in the education and training of all health professionals, not just doctors, who influence the prescribing process. 
Prescribers are making decisions in the face of immense clinical and health system complexity. Appropriate deprescribing needs to be regarded as equally important and achievable as appropriate initiation of new medications. Understanding how prescribers perceive and react to prescribing and deprescribing contexts is the first step to designing policy initiatives and health system reforms that will minimise inappropriate overprescribing.

\section{Author affiliations}

${ }^{1}$ Centre of Research Excellence in Quality \& Safety in Integrated PrimarySecondary Care, School of Medicine, The University of Queensland, Brisbane, Queensland, Australia

${ }^{2}$ Charming Institute, Camp Hill, Brisbane, Queensland, Australia

${ }^{3}$ School of Pharmacy, The University of Queensland, Brisbane, Queensland, Australia

${ }^{4}$ Department of Internal Medicine and Clinical Epidemiology, Princess

Alexandra Hospital, Woolloongabba, Queensland, Australia

Acknowledgements The authors thank the University of Queensland librarians Mr Lars Eriksson and Ms Jill McTaggart for their assistance in developing the search strategy and Ms Debra Rowett for her invaluable insights when scoping the search and developing the manuscript.

Contributors IS conceived the paper, the scope of which was refined by all authors. KA searched the literature, led the data analysis and drafted the manuscript. IS and DS read articles and assessed the data analysis for comprehensiveness and reliability. IS, DS and CF provided critical comments and contributed to the interpretation of the analysed results and framework development. All authors read, revised and accepted the final draft.

Funding KA and IS are funded through a National Health and Medical Research Council grant under the Centre of Research Excellence Quality \& Safety in Integrated Primary/Secondary Care (Grant ID, GNT1001157).

Competing interests KA received a speaker honorarium for an Australian Association of Consultant Pharmacy presentation. DS reports personal fees from the National Prescribing Service, outside the submitted work.

Provenance and peer review Not commissioned; externally peer reviewed.

Data sharing statement Data used to develop the tables and figures presented in this article are available by emailing the corresponding author, Kristen Anderson, k.anderson8@uq.edu.au.

Open Access This is an Open Access article distributed in accordance with the Creative Commons Attribution Non Commercial (CC BY-NC 4.0) license, which permits others to distribute, remix, adapt, build upon this work noncommercially, and license their derivative works on different terms, provided the original work is properly cited and the use is non-commercial. See: http:// creativecommons.org/licenses/by-nc/4.0/

\section{REFERENCES}

1. Morgan T, Williamson M, Pirotta $M$, et al. A national census of medicines use: a 24-hour snapshot of Australians aged 50years and older. Med J 2012;196:50-3.

2. Qato DM, Alexander G, Conti RM, et al. Use of prescription and over-the-counter medications and dietary supplements among older adults in the united states. JAMA 2008;300:2867-78.

3. Price SD, Holman CD, Sanfilippo FM, et al. Are older Western Australians exposed to potentially inappropriate medications according to the Beers Criteria? A 13-year prevalence study. Australas J Ageing 2014;33:E39-48.

4. Guaraldo L, Cano FG, Damasceno GS, et al. Inappropriate medication use among the elderly: a systematic review of administrative databases. BMC Geriatr 2011;11:79.

5. Aparasu R, Mort J. Inappropriate prescribing for the elderly: beers criteria-based review. Ann Pharmacother 2000;34:338-46.
6. Opondo D, Eslami S, Visscher S, et al. Inappropriateness of medication prescriptions to elderly patients in the primary care setting: a systematic review. PLOS ONE 2012;7:e43617.

7. Roughead EE, Anderson B, Gilbert AL. Potentially inappropriate prescribing among Australian veterans and war widows/widowers. Intern Med J 2007;37:402-5.

8. Byles JE, Heinze R, Nair BK, et al. Medication use among older Australian veterans and war widows. Intern Med J 2003;33:388-92.

9. Stafford AC, Alswayan MS, Tenni PC. Inappropriate prescribing in older residents of Australian care homes. J Clin Pharm Ther 2011;36:33-44.

10. Somers M, Rose E, Simmonds D, et al. Quality use of medicines in residential aged care. Aust Fam Physician 2010;39:413-16.

11. Cahir C, Bennett $K$, Teljeur $C$, et al. Potentially inappropriate prescribing and adverse health outcomes in community dwelling older patients. Br J Clin Pharmacol 2014;77:201-10.

12. Dedhiya SD, Hancock E, Craig BA, et al. Incident use and outcomes associated with potentially inappropriate medication use in older adults. Am J Geriatr Pharmacother 2010;8:562-70.

13. Kalisch LM, Caughey GE, Barratt JD, et al. Prevalence of preventable medication-related hospitalizations in Australia: an opportunity to reduce harm. Int J Qual Health Care 2012;24:239-49.

14. Carey IM, De Wilde S, Harris T, et al. What factors predict potentially inappropriate primary care prescribing in older people? Analysis of UK primary care patient record database. Drugs Aging 2008;25:693-706.

15. Lai HY, Hwang SJ, Chen YC, et al. Prevalence of the prescribing of potentially inappropriate medications at ambulatory care visits by elderly patients covered by the Taiwanese National Health Insurance program. Clin Ther 2009;31:1859-70.

16. Meurer WJ, Potti TA, Kerber KA, et al. Potentially inappropriate medication utilization in the emergency department visits by older adults: analysis from a nationally representative sample. Acad Emerg Med 2010;17:231-7.

17. Alldred DP. Deprescribing: a brave new word? Int J Pharm Pract 2014;22:2-3.

18. World Health Organisation. Guide to Good Prescribing —A Practical Manual. Chapter 11. STEP 6: Monitor (and stop?) the treatment. 1994.

19. NPS: Better Choices BH. Competencies required to prescribe medicines: putting quality use of medicines into practice. Sydney: National Prescribing Service Limited, 2012.

20. Reeve E, To J, Hendrix I, et al. Patient barriers to and enablers of deprescribing: a systematic review. Drugs Aging 2013;30:793-807.

21. Dixon-Woods M, Bonas S, Booth A, et al. How can systematic reviews incorporate qualitative research? A critical perspective. Qual Res 2006;6:27-44.

22. Tong A, Flemming $\mathrm{K}$, Mclnnes $\mathrm{E}$, et al. Enhancing transparency in reporting the synthesis of qualitative research: ENTREQ. BMC Med Res Methodol 2012;12:181.

23. Mays N, Pope C, Popay J. Systematically reviewing qualitative and quantitative evidence to inform management and policy-making in the health field. J Health Serv Res Policy 2005;10(Suppl 1):6-20.

24. InterTASC Information Specialists' Sub-Group. Filters to Identify Qualitative Research. Secondary Filters to Identify Qualitative Research. https://sites.google.com/a/york.ac.uk/ issg-search-filters-resource/filters-to-identify-qualitative-research

25. Tong A, Sainsbury P, Craig J. Consolidated criteria for reporting qualitative research (COREQ): a 32-item checklist for interviews and focus groups. Int J Qual Health Care 2007;19:349-57.

26. Hannes K. Chapter 4: Critical appraisal of qualitative research. In: Noyes J, Booth A, Hannes K, et al., eds. Supplementary Guidance for Inclusion of Qualitative Research in Cochrane Systematic Reviews of Interventions. Version 1 (updated Aug 2011). Cochrane Collaboration Qualitative Methods Group, 2011. http://cqrmg. cochrane.org/supplemental-handbook-guidance

27. Thomas J, Harden A. Methods for the thematic synthesis of qualitative research in systematic reviews. BMC Med Res Methodol 2008;8:45.

28. Tong A, Lesmana B, Johnson DW, et al. The perspectives of adults living with peritoneal dialysis: thematic synthesis of qualitative studies. Am J Kidney Dis 2013;61:873-88.

29. Britten N, Brant S, Cairns A, et al. Continued prescribing of inappropriate drugs in general practice. J Clin Pharm Ther 1995;20:199-205.

30. Moen J, Norrgard S, Antonov K, et al. GPs' perceptions of multiplemedicine use in older patients. J Eval Clin Pract 2010;16:69-75.

31. Schuling J, Gebben H, Veehof LJG, et al. Deprescribing medication in very elderly patients with multimorbidity: the view of Dutch GPs. A qualitative study. BMC Fam Pract 2012;13:56.

32. Anthierens S, Tansens A, Petrovic M, et al. Qualitative insights into general practitioners views on polypharmacy. BMC Fam Pract 2010;11:65. 
33. Fried TR, Tinetti ME, lannone L. Primary care clinicians' experiences with treatment decision making for older persons with multiple conditions. Arch Intern Med 2011;171:75-80.

34. Dybwad TB, Kjolsrod L, Eskerud J, et al. Why are some doctors high-prescribers of benzodiazepines and minor opiates? A qualitative study of GPs in Norway. Fam Pract 1997;14:361-8.

35. Damestoy N, Collin J, Lalande R. Prescribing psychotropic medication for elderly patients: some physicians' perspectives. CMAJ 1999;161:143-5.

36. Iliffe $\mathrm{S}$, Curran HV, Collins $\mathrm{R}$, et al. Attitudes to long-term use of benzodiazepine hypnotics by older people in general practice: findings from interviews with service users and providers. Aging Ment Health 2004:8:242-8.

37. Parr JM, Kavanagh DJ, Young RM, et al. Views of general practitioners and benzodiazepine users on benzodiazepines: a qualitative analysis. Soc Sci Med 2006;62:1237-49.

38. Cook JM, Marshall R, Masci C, et al. Physicians' perspectives on prescribing benzodiazepines for older adults: a qualitative study. J Gen Intern Med 2007;22:303-7.

39. Rogers A, Pilgrim D, Brennan S, et al. Prescribing benzodiazepines in general practice: a new view of an old problem. Health (London) 2007;11:181-98.

40. Dickinson R, Knapp $\mathrm{P}$, House $\mathrm{AO}$, et al. Long-term prescribing of antidepressants in the older population: a qualitative study. $\mathrm{Br} J$ Gen Pract 2010;60:e144-55.

41. Subelj M, Vidmar G, Svab V. Prescription of benzodiazepines in Slovenian family medicine: a qualitative study. Wiener klinische Wochenschrift 2010;122:474-8.

42. Iden KR, Hjorleifsson S, Ruths S. Treatment decisions on antidepressants in nursing homes: a qualitative study. Scand J Prim Health Care 2011;29:252-6.

43. Flick U, Garms-Homolová V, Röhnsch G. "And mostly they have a need for sleeping pills": physicians' views on treatment of sleep disorders with drugs in nursing homes. J Aging Stud 2012;26:484-94

44. Raghunath AS, Hungin APS, Cornford CS, et al. Use of proton pump inhibitors: an exploration of the attitudes, knowledge and perceptions of general practitioners. Digestion 2005;72:212-18.

45. Wermeling M, Himmel W, Behrens G, et al. Why do GPs continue inappropriate hospital prescriptions of proton pump inhibitors? A qualitative study. Eur J Gen Pract 2013;20:174-80.

46. Cantrill JA, Dowell J, Roland M. Qualitative insights into general practitioners' views on the appropriateness of their long-term prescribing. Int J Pharm Pract 2000;8:20-6.

47. Frich JC, Hoye S, Lindbaek M, et al. General practitioners and tutors' experiences with peer group academic detailing: a qualitative study. BMC Fam Pract 2010;11:12.

48. Clyne B, Bradley MC, Hughes CM, et al. Addressing potentially inappropriate prescribing in older patients: development and pilot study of an intervention in primary care (the OPTI-SCRIPT study). BMC Health Serv Res 2013;13:307.

49. Spinewine A, Swine C, Dhillon S, et al. Appropriateness of use of medicines in elderly inpatients: qualitative study. BMJ 2005;331:935

50. Ostini R, Hegney D, Jackson C, et al. Knowing how to stop: ceasing prescribing when the medicine is no longer required. J Manag Care Pharm 2012;18:68-72.

51. Ritov I, Baron J. Status-quo and omission biases. J Risk Uncertainty 1992;5:49-61.

52. Spranca M, Minsk E, Baron J. Omission and commission in judgment and choice. J Exp Soc Psychol 1991;27:76-105.

53. Tsalatsanis A, Hozo I, Vickers A, et al. A regret theory approach to decision curve analysis: a novel method for eliciting decision makers' preferences and decision-making. BMC Med Inform Decis Mak 2010;10:51.

54. Reeve E, Shakib S, Hendrix I, et al. The benefits and harms of deprescribing. Med J Aust 2014;201:386-9.

55. Cullinan S, O'Mahony D, Fleming A, et al. A meta-synthesis of potentially inappropriate prescribing in older patients. Drugs Aging 2014;31:631-8.

56. Bradley CP. Factors which influence the decision whether or not to prescribe: the dilemma facing general practitioners. Br J Gen Pract 1992;42:454-8.

57. Butler CC, Rollnick S, Pill R, et al. Understanding the culture of prescribing: qualitative study of general practitioners' and patients' perceptions of antibiotics for sore throats. BMJ 1998;317:637-42.

58. Cohen D, McCubbin M, Collin J, et al. Medications as social phenomena. Health 2001;5:441-69.

59. Reeve E, Shakib S, Hendrix I, et al. Review of deprescribing processes and development of an evidence based, patient-centred deprescribing process. Br J Clin Pharmacol 2014;78:738-47.

60. Kaur S, Mitchell G, Vitetta L, et al. Interventions that can reduce inappropriate prescribing in the elderly. Drugs Aging 2009;26:1013-28.

61. Patterson S, Hughes $\mathrm{C}$, Kerse $\mathrm{N}$, et al. Interventions to improve the appropriate use of polypharmacy for older people. Cochrane Database Syst Rev 2012;5:CD008165.

62. Azermai M, Vander Stichele RRH, Van Bortel LM, et al. Barriers to antipsychotic discontinuation in nursing homes: an exploratory study. Aging Ment Health 2014;18:346-53.

63. Bourgeois J, Elseviers MM, Azermai M, et al. Barriers to discontinuation of chronic benzodiazepine use in nursing home residents: perceptions of general practitioners and nurses. Eur Geriatr Med 2013;5:181-7.

64. Iyer S, Naganathan V, McLachlan A, et al. Medication withdrawa trials in people aged 65 years and older. Drugs Aging 2008;25: 1021-31.

65. Scott I, Anderson K, Freeman C, et al. First do no harm: a real need to deprescribe in older patients. Med J Aust 2014;201:309-92. 